\title{
Discussion on Blended Learning for Computer Basic Course on Moodle Platform
}

\author{
Juan guo ${ }^{1, \text { a }}$ \\ ${ }^{1}$ ShiJiaZhuang Vocational Technology Institute, 050081, hebei , china \\ asjzpt_wyh@126.com
}

Keywords: Blended learning, Moodle, Computer Basic Course.

\begin{abstract}
Blended learning is E-learning and traditional classroom learning from the product integration to separate, is the "E-learning" transcendence and upgrading. Blended learning can play both teacher guidance, inspiration, leading, monitoring of the teaching process, but also fully embodies the student body as a learning process initiative, enthusiasm and creativity. Based on this, a blended learning for computer basic course on moodle platform to explore. This article describes the hybrid teaching philosophy and instructional platform for sharing software Moodle, to explore basic computer courses at the university to use a hybrid of teaching and the university based on the Moodle platform, a computer-based curriculum design.
\end{abstract}

\section{Introduction}

In recent years, many colleges adopt a multi-media learning resources, online learning communities and new online learning environment to constitute of network technology platform for teaching. Under this environment using rich multimedia resources and the Internet, can lead to student motivation and learning initiative. Development of the Internet makes the network teaching change the traditional teaching methods growing at an alarming rate. This method of learning has rich multimedia resources, interactive and other unique advantages. However, this teaching method, due to the lack of teachers as the leading teaching process, student learning doesn't reach expected ideals. Thus, combined the network teaching with traditional teaching to play their respective advantages, can build a new hybrid teaching model to achieve the best teaching results. Blended learning ${ }^{[1]}$ is E-learning and traditional classroom learning from the product integration to separate, is the "E-learning" transcendence and upgrading. Based on this, a blended learning for computer basic course on moodle platform to explore.

\section{Blended learning relevant Overview and Moodle Introduction}

Blended learning relevant Overview. Blended learning ${ }^{[2]}$ is an organic integration of face to face classroom teaching and digital teaching. Blended learning makes teaching concepts and teaching mode change, makes role and capacity as well as the role of student teachers have changed. The purpose of blended learning is the integration advantages of teaching and network teaching in the classroom. Blended learning using Collective teaching form mainly based on teacher taught, team-based forms of teaching "cooperative" concept, self-learning-based teaching. Blended learning teaching process includes introducing courses, event organization, learning support and teaching evaluation four links.

In blended learning, "blended" refers to a mixture of learning theory, a mixture of learning resources, a mixture of learning environment, a mixture of learning styles.Blended learning teaching process is primarily a combination advantages of traditional classroom teaching and E-learning teaching, is to achieve a certain teaching objectives, and based on space-time environment in which teachers and students, the learners effectively organized activities a teaching process. The four key aspects of blended learning teaching process is shown as Figure 1: 


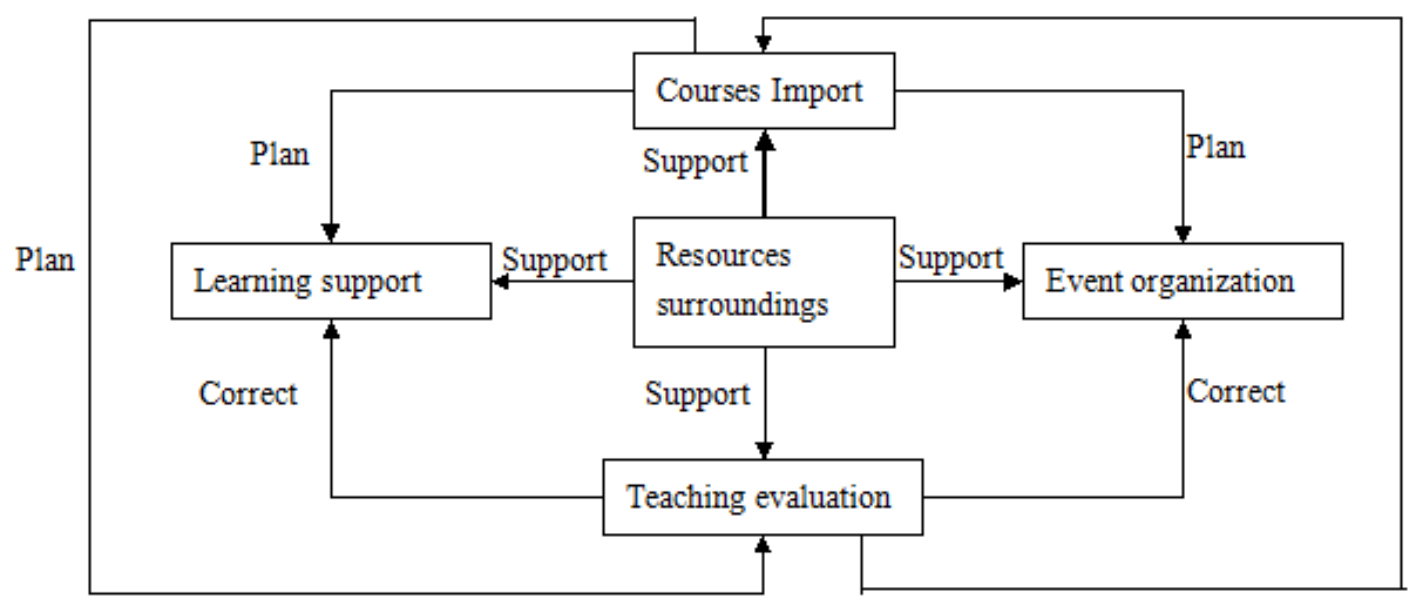

Fig.1 The four key aspects of blended learning teaching process

From Fig.1, we can know that blended learning is similar traditional classroom teaching. It consists of four different key teaching composition, namely the curriculum import, event organization, learning support and teaching evaluation.

Moodle Introduction. Moodle ${ }^{[3]}$ is an Australian teacher Martin Dougiamas developed course management system based on constructivist educational theory, and it is a free open-source software. It has been widely used in Asia.

The word Moodle is the short of Modular Object-Oriented Dynamic Learning Environment, namely modular object-oriented dynamic abbreviation learning environment. It is a software package used to build Internet-based courses and web sites. Moodle platform based on social constructivist teaching ideas, namely educators (teacher) and learners (students) are equal subject in the teaching activities, they collaborate with each other, based on their existing experience and co-construction of knowledge.

\section{The use of blended learning in basic computer courses}

Because the computer knowledge and software updates are very fast, but also to the computer's hardware configuration also has certain requirements, the traditional teaching is lagging behind in terms of textbooks, teaching facilities, laboratory teaching, etc., can not be the latest, most practical knowledge taught to students . The learner-based Blended Learning online has the autonomy, inquiry, collaborative learning characteristics, rich network resources to provide students with the latest and most practical knowledge and technology.

Improve the development of the Internet and quality of life, making the computer has become the necessities of life, the development of the social environment also requires us to master the computer knowledge and skilled operation of the computer. With the arrival of the $3 \mathrm{G}$ era, wireless Internet will appear in the explosive growth of broadband Internet access has become an important feature of the phone, which carry more anywhere blended learning facilitated.

Based on computer-based teaching model of blended learning, traditional teaching methods can be changed step by step formula and forcibly instill rigid teaching methods to classroom teaching and online teaching organically combine better address the many problems that exist in conventional teaching, for students learning ability, practical ability and the spirit of exploration, to promote teaching optimization plays an important role.

\section{Design of Blended Learning for Computer Basic Course on Moodle Platform}

Blended Learning is to be solved "Why teach", "what to teach" and "how to teach" problem. The ultimate goal is to come to achieve the desired goals through the design and implementation of teaching optimization of teaching programs.

Teaching content design. In blended learning, the courses focus on the overall planning and instructional design course the whole idea: First Blended Learning learners and learning objects to 
conduct a comprehensive analysis, in order to establish general teaching objectives of the course; then, on this basis, analysis of the development of each chapter, each unit until teaching objectives for each knowledge point; in addition to analyzing the structure of the learner's knowledge and ability, and eventually form a complete blended learning target system. With detailed teaching objectives, the next step in order to better select and teaching activities of teaching media design.

American educators Bloom's team since the 1950s, made a systematic study for the classification of educational goals. The educational goals divided into its cognitive, emotional and motor skills three areas:

Cognitive learning is the learning of knowledge, intellectual skills and problem-solving skills. Its characteristics are the acquisition and application of knowledge. Teaching target cognitive domains, from junior to senior is divided into knowledge, comprehension, application, analysis, synthesis, evaluation of six levels, which is shown as Figure 2, it is Broome cognitive teaching goals hierarchical graph:

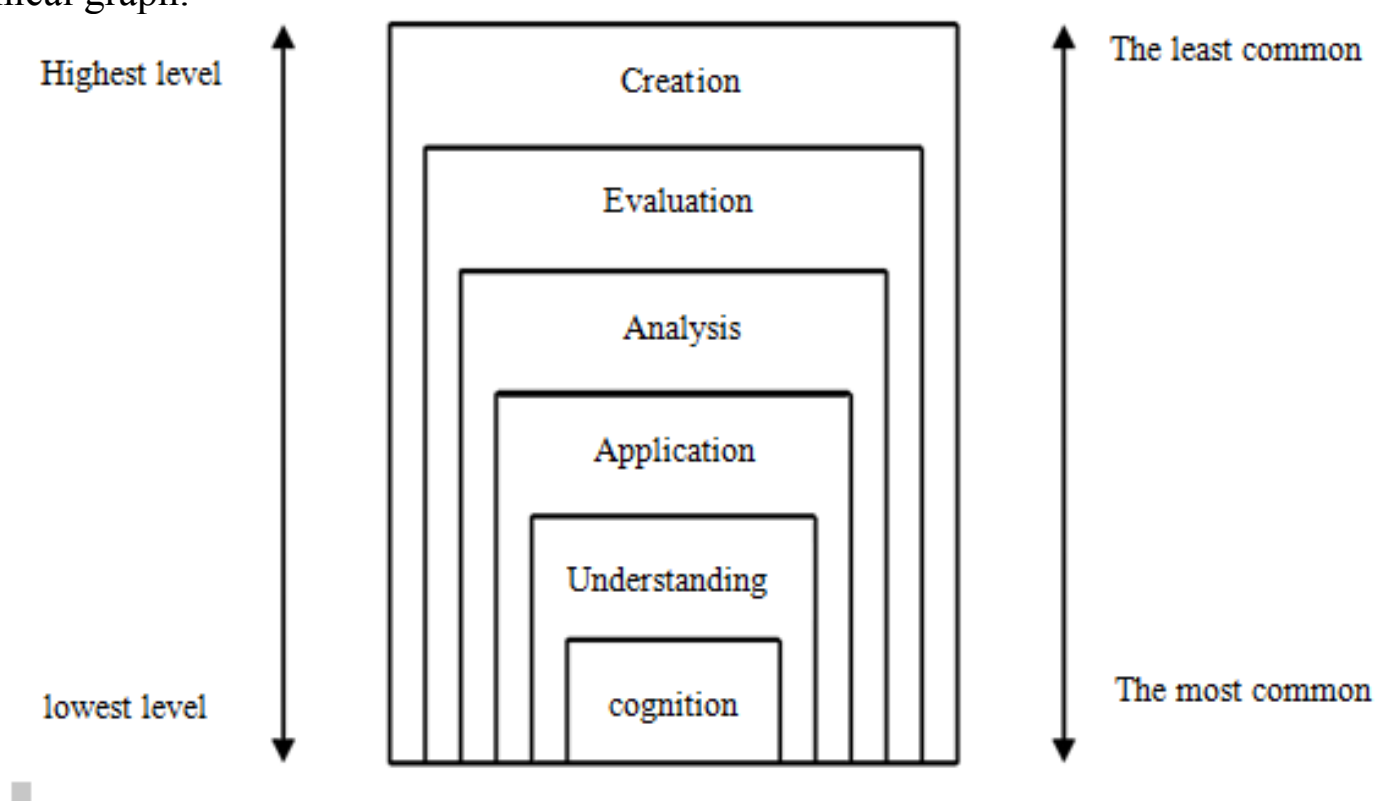

Fig.2 Broome cognitive teaching goals hierarchical graph

In Fig. 2, we know the target level is defined as information recall; understanding the target level is defined as the interpretation of the information in their own languages; application target level is defined as the knowledge to new situations; and analysis of the target level defined the decomposition of knowledge to identify links between the various parts; evaluation target level is defined as the judge according to certain criteria; create target level is defined as the combination of individual components to form a new whole.

The acquisition of motor skills is an ability, the results of study of the performance of the body's rapid, accurate, smooth and coordinated action. Emotional affairs learners to view and actions taken. Emotional class learning content can be divided into two character classes and class attitudes. Morality is an individual pursuant to certain social and moral conduct actions manifested some stable characteristics. Attitudes influence individual behavior is formed by studying selected internal state.

Moodle system installation settings. In Moodle system ${ }^{[4]}$, with the identity of the manager of the landing set good teacher, syllabus, teacher and student users to add, so that students can choose courses and teachers.

Resource Data section design. According to the needs of students can learn the information section of the import in. You can use TXT, PPT, WORD format.

Design a video library. Mainly because some workable some videos, deepen familiar with the use and understanding of students on it.

Remote Communication Design. You can add an AC design activities in the learning unit. Teachers can choose activities according to the needs and characteristics of teaching content. Some 
theories of activities can be used to create other forms of community WIKI allow members to modify, organize knowledge collected. In addition, Tencent QQ is very popular today, can provide a platform for the exchange by the QQ group QQ group and forum comes to students. Teachers also can answer in time for students, students can discuss the answer to each other,

Assessment of the design. Teachers can be arranged according to the contents of each chapter in Moodle system related tasks, test questions, etc. These can be the actual situation of the students to be a general understanding, and collected the students basic computer knowledge to grasp the situation.

\section{Conclusion}

Through Moodle system, allowing students to master basic computer knowledge, can greatly improve student learning initiative. Computer is a requirement strong operational discipline, It relies solely on the theory of the class with the knowledge to educate students, but after-school not digest, actually counterproductive. Through this system allows students to master basic computer knowledge at the same time, we can also do not understand or some knowledge beyond textbooks have deeper understanding. Hope the discussion to the blended learning, so we can provide reference to the research personnel.

\section{References}

[1] K.K.He. From Blendinglearning look New Development of Educational Technology Theory.J. EDUCATIONAL study, 4 (2004).

[2] J.H.Li. Moodle course design .M. Shanghai: Shanghai Education Press, 11,(2007).

[3] Driscon M.Blended learning-How to Integrate Online and TraditionalLearning.[EB/OL]. http://www.kogan-page.co.uk, 2003-16-20.

[4] Blackboard vs Moodle[EB/OL]. http://www.humboldt.edu/jdvl/Moodle/all.html. 